\title{
CORTESÍA ENTRE FRONTERAS. LOS JESUITAS EXPULSOS Y EL DEBATE SOBRE LA CIVILIDAD EN EL SIGLO XVIII: LORENZO HERVÁS Y PANDURO Y FRANCISCO AZNAR*
}

\author{
POR \\ MÓNICA BOLUFER² \\ Universitat de València
}

\section{RESUMEN}

Este trabajo estudia la aportación de los jesuitas expulsos en el siglo XVIII al debate sobre el carácter universal o culturalmente específico de la civilidad, a partir del análisis de dos obras de Lorenzo Hervás y Panduro y Francisco Aznar (la Historia de la vida del hombre y la Instrucción civil y cristiana), ambas versiones castellanas de obras publicadas en italiano. Se argumenta que la experiencia personal y colectiva de los miembros de la Compañía de Jesús como misioneros y como exiliados en Italia tras la expulsión de los territorios de la monarquía hispánica propició una reflexión de particular interés sobre la dimensión universal de la urbanidad, sobre sus aspectos relativos y culturalmente variables y, en última instancia, sobre la superioridad de las costumbres europeas.

PALABRAS CLAVE: jesuitas; urbanidad; civilidad; civilización; educación; lenguaje; diferencias culturales; traducción; mediación cultural; Ilustración.

\section{CIVILITY ACROSS FRONTIERS. JESUITS IN EXILE AND THE DEBATE ON POLITENESS IN THE EIGHTEENTH CENTURY: LORENZO HERVÁS Y PANDURO AND FRANCISCO AZNAR}

\begin{abstract}
This essay focuses on the contribution of jesuits in exile in the eighteenth century to the debate on the universal nature or cultural specificity of politeness. It does so by analizing two works by Lorenzo Hervás y Panduro and Francisco Aznar (Historia de la vida del Hombre and Instrucción civil y cristiana), both of them Spanish versions of Italian originals. My contention is that the individual and collective experience of the members of the Society of Jesus, as missionaries and as exiles in Italy after being expelled from the Hispanic monarchy, stimulated interesting reflections on the universal dimensions of politeness, on its cultural variations and, ultimately, on the superiority of European manners.
\end{abstract}

KEY WORDS: Jesuits; politeness; civility; civilization; education; language; cultural differences; translation; cultural mediation; Enlightenment.

Cómo CITAR este artículo / Citation: Bolufer, Mónica. 2019. «Cortesía entre fronteras. Los jesuitas expulsos y el debate sobre la civilidad en el siglo XVIII: Lorenzo Hervás y Panduro y Francisco Aznar». Hispania Sacra 71, 144: 603-618. https://doi.org/10.3989/ hs.2019.043

Recibido/Received 01-06-2018

Aceptado/Accepted $\quad$ 04-08-2018

* Este trabajo se enmarca en el proyecto de investigación Construcciones del yo: narraciones y representaciones del sujeto moderno, entre lo individual y lo colectivo (ss. XVII-XIX), HAR2014-53802-P, financiado por el Ministerio de Ciencia, Innovación y Universidades. Debo agradecer sus aportaciones de información y sus sugerencias a una versión anterior a Niccolò Guasti, Inmaculada Fernández Arrillaga y Enrique Giménez, así como a los evaluadores anónimos de la revista Hispania Sacra.

2 monica.bolufer@uv.es / ORCID iD: https://orcid.org/0000-0002-6532-4191. 


\section{LOS JESUITAS Y LA CORTESÍA: EXPERIENCIAS Y REFLEXIONES}

Hace ya tiempo que la historia cultural y la llamada «historia global» vienen interesándose por el papel de la Compañía de Jesús y de sus miembros individuales como agentes de lo que ha dado en llamarse - utilizando el concepto acuñado por el antropólogo Edward EvansPritchard- "traducción cultural», es decir adaptación o «domesticación» de elementos de una cultura a otra. En la época moderna, los jesuitas, diseminados por todos los puntos del globo, ejercieron como interesantes (y no neutrales, sino interesados) mediadores o go between entre culturas (Ramada Curto 2005; Rubiés 2005; Burke 2007). En virtud de la labor misionera de la orden, contribuyeron de manera fundamental a la producción de saberes sobre sociedades alejadas de las europeas y a la reflexión acerca del carácter mutable de las costumbres (Mantecón Sardiñas 2014; Rubiés 2017). En el ámbito de la evangelización, el sincretismo ignaciano dio lugar a la polémica de los ritos, en la cual franciscanos y dominicos acusaron a los jesuitas ante la Congregación de Propaganda Fide de aceptar como lícitas ciertas ceremonias confucianas con el argumento de que pertenecían al terreno de las costumbres y por ello a la esfera civil y no religiosa; el papa Benedicto XIV instaría a la Compañía, en dos bulas de 1742 y 1744, a mantener la pureza del culto divino (Giménez 2012: 244). Brillaron también en la práctica de la traducción, tanto del latín y de lenguas europeas modernas a otras no europeas (para servir a la evangelización) como entre unos idiomas europeos y otros, especialmente el italiano, español y francés: Peter Burke (2007) atribuye a traductores jesuitas más de 600 traducciones publicadas de unas lenguas europeas a otras en la Edad Moderna, sobre todo - pero no solo- obras de otros compañeros de orden. ${ }^{2}$

Los miembros de la Compañía de Jesús tuvieron una presencia muy destacada en la polémica del Nuevo Mundo (Gerbi 1960): el amplio debate, de alcance europeo y americano, que se sostuvo en el siglo XVIII sobre los fundamentos y las prácticas del colonialismo, sobre la naturaleza de América y sobre el propio concepto de «civilización». Por una parte, muchos jesuitas españoles, desde su exilio en Italia, participaron en la campaña apologética orquestada por el gobierno de Carlos III (con particular empeño de Floridablanca) para responder a las críticas que escritores británicos y franceses habían formulado contra la empresa conquistadora española, calificándola de brutal (en obras como la Histoire philosophique et politique des établissements et du commerce des Européens dans les deux Indes -1770 - del abate Guillaume-Thomas Raynal y, con mucho menor énfasis, la History of America -1777- del historiador escocés William Robertson). Lo hicieron sosteniendo el carácter humano y benéfico de la conquista española (cuyos abusos habrían sido siempre debidos a desmanes individuales, rápidamente atajados por la monarquía), lo que, paralelamente, les llevaba a subrayar la barbarie de las

2 En el escenario filosófico, los jesuitas adoptaron posturas eclécticas que les permitieron conciliar el tomismo con la ciencia moderna y las aportaciones epistemológicas del racionalismo, el atomismo, el empirismo y hasta el newtonismo, realizando así contribuciones científicas destacadas, en especial en las matemáticas (Romano 1999; Navarro Brotons 2014). sociedades indígenas sobre las cuales los conquistadores habrían impuesto un orden político, moral, civil y religioso superior (Guasti 2011 y 2014; Soriano 2013). Por otra parte, algunos jesuitas criollos terciaron en el debate - distinto pero entrelazado con el anterior - sobre la supuesta inferioridad natural y humana que atribuían a las Indias científicos europeos como el filósofo holandés al servicio de Prusia Cornelius de Pauw y el naturalista francés George-Louis Leclerc, conde de Buffon. Desde América, jesuitas como el novohispano Francisco Javier Clavijero defendieron, por el contrario, la riqueza natural y cultural del continente y contribuyeron a construir una historia basada en la autoridad de la observación y la experiencia sobre el terreno (Cañizares Esguerra 2007; Sebastiani 2011).

Sin embargo, hay un asunto en el cual no se ha puesto demasiada atención al analizar la abundante producción intelectual de los jesuitas: el papel que desempeñaron en el intenso debate dieciochesco sobre el significado, las funciones y la justificación moral de la civilidad, en una época que vio multiplicarse y ampliarse socialmente las aspiraciones a dominar las reglas del comportamiento cortés y refinado, a medida que se debilitaban los principios jerarquizadores estamentales. ${ }^{3}$ Y más específicamente, en la actualización de lo que constituía un tópico dentro del género de los manuales de cortesía: la idea de que los códigos corteses, como en general las costumbres, variaban de forma acusada tanto en el tiempo como en el espacio, de modo que aquello que aparecía como racional e incluso natural en un momento y un lugar determinados podía resultar, por el contrario, extraño, incomprensible y aun ofensivo en otro contexto. Desde el siglo XVI, la literatura de urbanidad venía insistiendo en que sus destinatarios, en especial los varones nobles que podían tener que "correr Cortes» y ejercer funciones diplomáticas en otros países, habían de aprender a desenvolverse observando las costumbres ajenas, entre ellas los preceptos de civilidad, y adaptándose a ellas. Esa conciencia se hizo más acusada a medida que la expansión -colonial, comercial, diplomática y religiosa- de Europa y los relatos de viajes, eruditos o etnográficos que daban a conocerla a un público amplio ponían en contacto a los europeos con sociedades regidas por costumbres y códigos extremadamente distintos. Ello se hacía patente de forma visible, entre otros aspectos, en sus reglas de urbanidad, que podían causar graves malentendidos, al interpretarse como irrespetuosos gestos que en otra cultura expresaban, precisamente, cortesía y reconocimiento.

Los jesuitas, como misioneros en tierras remotas, desde América al Extremo Oriente, tuvieron ocasión de experimentar esos equívocos y de reflexionar sobre ellos, aunque su experiencia no siempre les evitó incurrir en embarazosos errores o interpretaciones incorrectas. Así lo muestra la conmovedora - y reveladora - historia del chino converso Jean $\mathrm{Hu}$, quien al viajar a Francia a principios del siglo XVIII al servicio del erudito jesuita P. Foucquet para ayudarle en sus transcripciones de textos chinos antiguos, vio cómo sus gestos de practicar el kowtow o ritual de reverencias ante un crucifijo o de negarse a tomar asiento ante el arzobispo por deferencia a la posición jerárquica de este eran tomados como signos de descortesía, herejía e incluso locura (Spence 2009).

\footnotetext{
3 Me he ocupado recientemente de este debate en Bolufer 2019.
} 
En tanto que miembros de una orden con una larga tradición misionera desde América al Extremo Oriente, los autores jesuitas nutrieron el acervo de observaciones acerca de la gran distancia cultural que mediaba entre las costumbres europeas y las de otras civilizaciones absolutamente distintas. Y al mismo tiempo, en calidad de educadores de las elites masculinas europeas, como preceptores privados y profesores de colegios de nobles, escribieron numerosas obras pedagógicas en las que concedían gran importancia a la formación civil y cortés, como correspondía a la posición social y ambiciones de sus educandos. El modelo educativo de la ratio studiorum practicado en los establecimientos de la Compañía de Jesús insistía en formar la destreza del cuerpo y el refinamiento de las maneras al tiempo que en controlar las pasiones del alma a través de la piedad y la contención (Pancera 1986; Botteri 2004). Así lo ponen de manifiesto las Regulae modestiae de Ignacio de Loyola (1555), frecuentemente reeditadas, y las constituciones de numerosos colegios jesuíticos, desde el Collegium Germanicum creado en 1542 en Roma para la instrucción del clero procedente de la Europa reformada al Colegio Imperial de Madrid, fundado en 1625, o el Col/legi o Seminari de Nobles de Cordelles.

Sin embargo, la historia de la Compañía de Jesús apenas ha puesto en relación esas dos dimensiones - misionera y pedagógica - de la actividad jesuítica y de su influencia en la producción de saberes. En este artículo pretendo explorar cómo los jesuitas españoles exiliados en Italia tras la expulsión incorporaron en su trabajo intelectual, especialmente en su producción de tratados pedagógicos y de urbanidad, una mirada particular, informada por la experiencia y el relato de misiones de sus compañeros de orden, y a la vez por su propia vivencia de intelectuales entre dos contextos, el italiano y el español. Y de forma más amplia, cómo se relacionaron esas dos tareas fundamentales de la orden, la misionera y la educativa; qué influencia tuvo el saber generado por sus misiones por Oriente y por América en las enseñanzas impartidas a sus alumnos europeos, y en qué medida pudo contribuir a extender la idea de la variabilidad de las costumbres, entre ellas las normas de cortesía, como signo de diferencia cultural y, en última instancia, de «civilización».

Para realizar una primera aproximación al tema, he escogido dos tratados escritos desde el exilio en Italia tras la expulsión de la Compañía de todos los territorios de la monarquía hispánica en 1767, previa a su total disolución en 1773. Allí, ante la mala acogida ofrecida por sus compañeros de orden italianos, y contando con precarios medios de vida, los exjesuitas españoles hubieron de buscar ocupación y formas de subsistencia que, apoyándose en su notable preparación, encontraron en muchos casos como preceptores privados de familias nobles y patricias, profesores de Universidades del centro y Norte de Italia (especialmente Bolonia y Ferrara), bibliotecarios y directores de instituciones educativas: seminarios, colegios, orfanatos (Batllori 1966; Giménez 2002; Guasti 2006, 2009: 258-266, 2013, 2015; Tietz 2001). Con frecuencia los que compusieron sus obras en lengua italiana aspiraron a difundirlas también en España, con el poco disimulado propósito de obtener pensiones del gobierno borbónico, y a tal efecto introdujeron en ellas alteraciones más o menos importantes, bien fuese para desarrollar, modificar o puntualizar su propio pensamiento o bien para adaptarlo a su circulación en un contexto sociocultural y político distinto. Así sucedió con los dos manuscritos existentes del Ensayo filosófico sobre los caracteres personales de Vicente Requeno y Vives (17431811), de los cuales, como ha estudiado Antonio Astorgano, la versión italiana de 1787, más concisa, sigue de cerca el modelo clásico de los Caracteres de Teofrasto, mientras que la castellana de 1800 resulta más moralizante, conservadora y antifilosófica, reflejando así la diferencia entre el contexto italiano prerrevolucionario y el de la España sumida en la reacción antifrancesa. ${ }^{4}$ Pero sucede también con las dos obras que analizaré a continuación: la Historia de la vida del Hombre de Lorenzo Hervás y la Instrucción útil a la juventud de Francisco Aznar.

\section{¿UNIVERSAL O ESPECÍFICA? LA URBANIDAD EN LA OBRA DE} HERVÁS Y PANDURO

Un texto interesantísimo sobre el tema lo constituye la reflexión que dedicó Lorenzo Hervás y Panduro (1735-1809) a la urbanidad en su monumental obra Historia de la vida del Hombre. Hervás fue un personaje singular, de amplísima erudición, ambición enciclopédica y espíritu ilustrado, de brillante carrera y gran prestigio entre sus antiguos compañeros de orden pese a su humilde origen (Astorgano 2010). Nacido en 1735 en el seno de una modesta familia de labradores manchegos, ingresó en la Compañía de Jesús en 1749 dentro de la provincia de Aragón (una de las más dinámicas entre las once que estructuraban la asistencia de España), se ordenó en 1760 y enseñó en Cáceres, en Madrid (donde dirigió el Seminario de Nobles, centro por excelencia de formación de los varones nobles) y en Murcia. Exiliado en Italia desde 1767, en el país de acogida se labró un medio de vida decoroso y excelentes relaciones con la nobleza local. Se estableció en Forlì hasta 1773, posteriormente en Cesena, como preceptor de los hijos del marqués de Chini, y finalmente en Roma, antes de volver a España en 1798, acogiéndose al decreto de Carlos IV que permitía el retorno gradual de los jesuitas expulsos; regresaría a Italia en 1802, fijando su residencia en Roma hasta su muerte en 1809.

Hervás ejerció un papel muy relevante en el universo del exilio jesuítico en Italia. La expulsión reunió en esos territorios a un gran número de ignacianos procedentes de los territorios de las monarquías hispánica y portuguesa antes residentes en la Península Ibérica, pero también en Asia y América, entre ellos numerosos misioneros e intelectuales. La forzosa cercanía propició lazos personales e intercambios culturales, estimulando así la producción de conocimientos. En ese contexto, Hervás estableció vínculos muy estrechos con diversos compañeros de orden, en particular con los procedentes del continente americano, entre ellos Francisco Javier Clavijero. Con ellos mantuvo trato personal y una intensa correspondencia, a través de las cuales ejerció, como ha destacado Nicolás Perrone, un cierto liderazgo intelectual en esa comunidad (Perrone 2012: 111). En sus obras se hace patente que se nutrió de informaciones

4 Requeno y Vives 2008. Véase el estudio introductorio de Antonio Astorgano: «El abate Vicente Requeno y Vives (1743-1811), restaurador de las artes grecolatinas y pensador»: XLVII-CC, particularmente el análisis de las variantes de los dos manuscritos: CXIV-CXXI. 
aportadas por jesuitas de todo el mundo, y muy especialmente de la América española, sobre las cuales elaboró sus reflexiones y sus teorías.

La obra cumbre de Hervás fue la enciclopédica Idea dell'Universo (1778-1792), dividida en once tomos que comprenden 21 volúmenes, estructurados a su vez en tres partes: una consagrada a la vida humana, otra a la cosmografía y otra, por último, a la lengua. Fue experto en cuestiones lingüísticas -en la década de 1780 publicó cuatro extensas obras sobre el origen, clasificación y funcionamiento de las lenguas del mundo, hasta el punto de que se le considera uno de los padres de la Filología comparada. ${ }^{5}$ Junto a estos trabajos, destaca entre sus obras la Reflexión sobre las causas de la revolución de Francia (1794), escrita en pleno periodo del Terror para indagar en las causas morales de la revolución, que él atribuye principalmente al jansenismo, tradicional enemigo de la Compañía de Jesús (Perrone 2013). Varias de sus publicaciones en italiano las tradujo, adaptó y amplió sustancialmente en castellano. Es el caso de la Historia de la vida del Hombre inspirada en la primera parte de su Idea dell'universo, que vio la luz en España en siete volúmenes entre 1789 y 1799 , después de que la censura obligase a suprimir la introducción del tomo primero, considerada peligrosa a la luz de los acontecimientos revolucionarios en Francia, e impidiese la publicación del 8o y último (Guasti 2018). Y ello a pesar de que su propósito era ofrecer una enciclopedia cristiana, compendio de saberes útiles que contraponer al enciclopedismo francés y a la llustración más radical.

La reflexión de Hervás sobre la urbanidad se enmarca en el contexto más amplio de su visión de la sociedad y la naturaleza humana. Una visión que incorpora a la idea cristiana de perfectibilidad moral del individuo (ayudado por la gracia divina) la preocupación ilustrada por valorar la evolución colectiva de las costumbres para distinguir en ellas lo universal de lo particular, lo intrínseco a la naturaleza de aquello contingente y sujeto a las variaciones culturales. En este sentido, por ejemplo, Hervás afirma que la distinción entre hombres y mujeres en cuanto a su educación, ocupaciones, espacios sociales y apariencia externa remite a la «razón natural» y es por ello universal, pudiéndose constatar en todas aquellas naciones que "adoptan los verdaderos principios de civilidad»; es decir, considera que la clara diferenciación social de los sexos frente a su relativa indiferenciación primitiva constituye uno de los signos de la auténtica civilización (Hervás 1789-1799, t. I, lib. III, cap. I: 318).

En la Historia de la vida del Hombre, dentro del libro titulado «El hombre en su virilidad» y, más específicamente, del tratado «Discursos políticos sobre el hombre y la sociedad civil», Hervás dedica un capítulo específico a la «Urbanidad

5 Catalogo delle lingue conosciute (1784-1785), traducido años después al castellano (Catálogo de las lenguas de las naciones conocidas y enumeración, división y clases de éstas según la diversidad de sus idiomas y dialectos, 1800-1805, 6 vols.), Origine, formazione, mecanismo ed armonia degli Idiomi (1785), Vocabolario poliglotto, con prolegomen sopra più de CL lingue (1787) y Saggio practico delle Lingue con prolegomeni e una raccolta di orazioni dominicali in più di trecento lingue e dialetti (1787). Asimismo, se interesó en Roma por aprender los métodos más modernos de educación para personas sordomudas, que dio a conocer en España con la obra titulada Escuela española de Sordomudos o arte para enseñarles a escribir y hablar el idioma español (1795). Sobre el uso que en la Historia de la vida del Hombre hizo Hervás de su amplia formación clásica, véase Perrone 2017. y cortesía en el comercio humano». ${ }^{6}$ En él reflexiona sobre la universal existencia de códigos de civilidad en las distintas sociedades y sobre sus variaciones en el tiempo y el espacio. En consonancia con el espíritu enciclopédico que anima su obra, lo que ofrece en ese apartado es algo distinto a lo que suelen brindar los manuales de cortesía: una disquisición moral y filosófica sobre el origen, valor y significado de la urbanidad, más que un conjunto de consejos sobre las distintas circunstancias en que cabe aplicarla. Su idea conductora adjudica a la urbanidad un triple carácter: como inclinación universal, como signo genérico de civilización y como conjunto de códigos específicos y culturalmente variables. En consonancia con ello, articula su propia reflexión en tres epígrafes titulados, respectivamente: I. «Urbanidad a título de justicia», II. «Urbanidad a título de decencia» y III. «Observación crítica de las expresiones de cortesía que se usan en los idiomas de las naciones civilizadas».

Así, por una parte, Hervás considera que, en su origen y su finalidad, la urbanidad constituye una inclinación natural $y$, por tanto, universal, que tiene por objeto asegurar tanto la armonía y suavidad en el trato entre los humanos como el respeto a las jerarquías. En ese sentido, es un patrimonio común de la humanidad, del que no carecen -al menos en cierta medida - ni siquiera las naciones menos civilizadas:

La sociedad humana nos quiere siempre urbanos y corteses, y la naturaleza misma, ilustrada por la buena educación, suele repugnar tanto a la falta de urbanidad como a los vicios morales. Aquella es inspirada por la naturaleza, que dicta e inclina a respetarse y honrarse mutuamente los hombres, según la diversa graduación de sus clases, como de hijos y padres, de discípulos y maestros, y de súbditos y superiores [...]. El mismo principio que naturalmente nos hace concebir en el ánimo la justa idea de la atención y respeto que debemos a nuestros semejantes, nos obliga a manifestarla y practicarla con palabras corteses y acciones comedidas y obsequiosas, por cuyo medio llega a introducir en la sociedad humana el método seguro de enlazarse gustosamente los hombres con el comercio recíproco y harmónico, y con el buen orden que debe existir en sus varias gerarquías. De aquí proviene que no hay nación, ni gremio de gentes, por bárbaras que sean, que no tengan su ceremonial escrito o impreso en la memoria (Ibídem: 310-311; cursiva añadida).

Los principios básicos de la urbanidad son, pues, en su opinión universales: "La razón natural inspira el mutuo respeto de los hombres, y ciertas ceremonias o acciones exteriores en circunstancias de alegría, dolor, agradecimiento y amor» (Ibídem: 311). Sin embargo, a un segundo nivel la urbanidad, en su grado más desarrollado, constituye un signo indicativo y una condición necesaria de una sociedad verdaderamente civilizada, lo que excluye a los pueblos «bárbaros» o "primitivos»: "Las naciones cultas añaden a estas ceremonias, que son efecto del instinto racional, otras con que se civiliza la sociedad humana y se enlazan más estrechamente sus miembros entre sí, y sus superiores» (Ibídem: 311).

No obstante, tal como sostenían los ilustrados, Hervás considera que el refinamiento de una sociedad no garantiza por sí mismo un nivel óptimo de urbanidad, sino que amenaza con llevar esta virtud al exceso. Para persuadir de ello y

\footnotetext{
6 Hervás 1789-1799, t. V, Libro V, tratado III, cap. IV: 310-338.
} 
abogar por un ideal de moderación y comedimiento, recurre a la comparación entre Oriente y Occidente, más concretamente entre las antiguas y refinadas sociedades china y japonesa y las sociedades europeas, ejercicio transcultural que fue común en el siglo XVIII. ${ }^{7}$ Así como en otras de sus obras, por ejemplo el Catálogo de las lenguas de las naciones conocidas, prestó una atención muy especial a las realidades americanas y utilizó ampliamente las informaciones proporcionadas por exjesuitas que habían vivido allí (Perrone 2012), a la hora de abordar la urbanidad en su Historia de la vida del Hombre se apoya más bien en noticias del Extremo Oriente, cuya procedencia no precisa pero que cabe suponer provenían de los datos recabados directamente de misioneros jesuitas, por contactos directos o epistolares, o bien reunidos a partir de la lectura de las obras de estos. A su juicio, como en general para los eruditos europeos, Japón y especialmente China no podían en modo alguno, en virtud de su larga historia y de la sofisticación de sus sistemas culturales, sociales y políticos, ser excluidas del conjunto de las «naciones cultas». Para las gentes de letras en los siglos XVII y XVIII, ambas naciones, y en particular esta última, constituían, de hecho, la prueba de que era posible alcanzar un alto grado de refinamiento en ausencia de la religión "verdadera» - la cristiana-, de cualquier religión revelada e incluso de una religión propiamente dicha, en la medida en que el confucianismo podía entenderse más bien como una filosofía que como un credo (Hazard 1941: 9-25). ${ }^{8}$ En esa época, el interés por lo oriental se extendió de los estudios eruditos al arte, la moda y la literatura, inspirando desde numerosas obras de ficción a las exquisitas chinoiseries propias de la decoración rococó. La intensificación de las relaciones comerciales con Oriente (que inundó el mercado europeo de productos de lujo y manufacturas exóticas) y las informaciones aportadas por misioneros y eruditos jesuitas tuvieron gran influencia en avivar esa fascinación.

Hervás evoca el sentimiento de extrañeza y desconcierto que muchos usos orientales provocan en los europeos, que según señala, también sucede a la inversa, para poner de relieve el carácter relativo de las costumbres: «muchas veces la disonancia proviene de la costumbre y genio diferente de las naciones, y así cada uno deberá acomodarse a las que se acostumbran en el país donde se halla, aunque sean contrarias a las del suyo propio» (Hervás 1789-1799, t. V, cap. IV: 317). El exjesuita hace un esfuerzo de ecuanimidad al señalar que ninguna sociedad está exenta de críticas, y que el contraste o "disonancia» cultural entre lo propio y lo ajeno permite aprender de la observación tanto aquello a imitar de los otros como lo que se debe rechazar. Probablemente informado a través de las noticias de sus compañeros sobre las instituciones, las costumbres y el gobierno chinos, señala la íntima relación existente en aquel país entre ceremonial y estructuras y obediencias políticas, que explica su regulación minuciosa. La idea de que cultivar el cumplimiento escrupuloso de las reglas y los tratamientos verbales de cortesía constituye una forma de mantener el orden político, ritualizando las expresiones de pleitesía y deferencia, la encontraremos años después en un humilde texto para uso de las escuelas rurales, cuya lección XII se titulaba «De las palabras más

\footnotetext{
7 Sobre los jesuitas y China, véanse entre otros Romano 2013 y 2016; Mantecón Sardiñas 2014.

8 Sobre el interés europeo por las culturas orientales en épocas anteriores, puede consultarse Brotton 2003.
}

usuales de cortesía» (Anónimo 1807: 33-40). El autor de esta obrita coincide a este respecto con Hervás, quien desarrollaba el argumento así:

Las naciones orientales miran el ceremonial de la urbanidad como medio eficaz y necesario para mantener entre todos sus miembros la unión y subordinación debida, y por esto sus respectivos gobiernos cuidan de promover en el pueblo el estudio de las ceremonias, de los títulos y de las expresiones correspondientes al carácter de cada persona. La nación china, y otras orientales que siguen su exemplo, han colocado el ceremonial entre las facultades más necesarias de la literatura de la sociedad civil (Hervás 1789-1799, t. V, cap. IV: 311).

Si bien considera "superfluas» muchas de las ceremonias propias de las naciones orientales, Hervás estima que algunas de sus costumbres pueden compararse ventajosamente con las europeas. Es el caso de la modestia que guardan en sus visitas, frente a la falta de compostura en palabras y acciones que se experimenta en los banquetes europeos, donde se come y bebe en exceso, se grita y canta sin recato y se ha convertido en moda entre personas encumbradas («de alto carácter») tratar sobre la religión en términos poco respetuosos (Ibídem: 321-322).

Pese a algunas concesiones como esta y a la atracción que sobre Hervás, como sobre tantos otros jesuitas y gentes de letras en Europa, ejercieron las culturas del Extremo Oriente, su posición no es en absoluto relativista. La comparación entre las costumbres orientales y las europeas se resuelve en última instancia a favor de estas últimas. De un lado, por motivos religiosos, en virtud de la innegable superioridad del cristianismo para todo creyente y en especial para un exreligioso como él. De otro lado, Hervás argumenta la superioridad europea - cabe subrayarlo- también en el orden cultural. Utiliza los ejemplos de China y Japón para advertir contra la excesiva rigidez y el carácter constrictivo que allí alcanza la etiqueta, como sucede con el complejísimo ceremonial de las visitas y convites, que describe en detalle (Ibídem: 318-320). Y cuando ridiculiza a quienes se obsesionan por los gestos más nimios de la cortesía, pone precisamente como ejemplo la extrema prolijidad que según él revisten los equivalentes chinos de los manuales de cortesía:

A éstos se había de dar la penitencia de que aprendiesen de memoria todos los galateos del mundo, y por apéndice uno de los libros chinos que tratan de cortesía, el qual contiene más de tres mil artículos, para que apagasen la sed de aprender ceremonias, pero básteles la pena de ser la burla y fábula de todas las conversaciones (Ibídem: 317).

Al castigar a los más escrupulosos a aprenderse de memoria todos los galateos, como se conocía a aquel género a partir de la fama del Galateo (1558) del también jesuita Giovanni Della Casa, Hervás juega irónicamente con los usos posibles de ese tipo de lecturas. En efecto, en la tradición de la cortesía nobiliaria se entendía que la persona verdaderamente civil no necesitaba leer manuales de civilidad, y si lo hacía era para ver reflejada en ellos su propia distinción, ratificándose en la seguridad de practicar la cortesía sin esfuerzo, con sprezzatura o elegante negligencia, más que para aprender sus detallados preceptos. La imagen de un lector que esforzadamente memoriza decenas de 
manuales para aplicar las reglas de cortesía en su vida cotidiana, constituye, pues, la antítesis del caballero o la dama que exhiben de manera espontánea una conducta siempre Ilena de gracia y elegancia, y remite más bien al estereotipo del advenedizo que trata de aparentar lo que no es.

Hervás sostiene que, frente a la regulación extrema de la cortesía que se practica en las sociedades que llama "ceremoniáticas» del Extremo Oriente, cierta flexibilidad en el trato resulta indispensable para que las relaciones humanas no resulten excesivamente envaradas: «Los europeos, menos ceremoniáticos que los orientales, no dexan de ser exactos en lo que substancialmente pide la urbanidad, a título de justicia y decencia» (Ibídem: 311). También a ese respecto, la comparación que establece en su obra se resuelve de modo favorable al conjunto de Europa, cuyos usos Hervás estima relativamente equilibrados en este aspecto: «juzgo que las naciones europeas, las quales concuerdan mucho en su ceremonial, son las más moderadas y las que menos tienen de ridículo y extravagante en esta materia» (Ibídem: 318; cursiva añadida).

Como se desprende de la afirmación anterior, el jesuita, acostumbrado al trato social en el entorno de las elites españolas e italianas, conoce la relativa similitud de las pautas de cortesía en las sociedades europeas, modelada por una larga tradición cultural común y por la amplia circulación paneuropea de personas, ideas y mercancías, incluidos los propios manuales de civilidad. Cierto es que se hace eco de los tópicos sobre la gravedad de los españoles, el carácter taciturno de los ingleses, la charlatanería de los italianos o la politesse afectada de los franceses: «Verdad es que algo se ha de conceder al ingenio de las naciones. Al francés, quando es saludado, es menester dexar que ponga en movimiento todos los miembros de su cuerpo que parece todo de goznes; al italiano, que hable por todas sus coyunturas; al inglés, que mantenga su silencio, y al español, que guarde su gravedad» (Ídem). Es su guiño humorístico a los viejos estereotipos, reactivados en el siglo XVIII en forma de "caracteres nacionales» en diversas polémicas intelectuales y políticas, como la sostenida a propósito de la aportación de España a la cultura europea. ${ }^{9}$ Sin embargo, Hervás es consciente de la creciente confluencia que los valores $y$ los estilos de vida habían experimentado en el siglo XVIII, de modo que en general $-y$ con excepción de estas pocas líneas - se refiere a los usos de cortesía europeos de forma conjunta, sin establecer distinciones entre unos países y otros.

A diferencia del primer nivel de la urbanidad, que para el exjesuita aragonés resulta plenamente universal, el segundo está limitado, en su opinión, a las «naciones cultas» o civilizadas. En todas ellas reina lo que él denomina la urbanidad "a título de justicia», cuyos principios pueden resumirse en el respeto a la edad, la sabiduría, el honor o la dignidad de las personas. La pedagogía humanista justificaba esa obligación como un reconocimiento a las jerarquías y, en última instancia, a Dios, de quien toda autoridad emana: en su afán educador, el humanista Erasmo de Rotterdam llegó a poner como ejemplo extremo la pleitesía que los cristianos deberían

9 A propósito de esta polémica, cuyo episodio más conocido fue el debate en torno al artículo «Espagne» de Masson de Morvilliers en la Encyclopédie méthodique, véanse, entre otros, Mestre 2003 y Diz 2000. rendir al poder político incluso en el hipotético caso de que recayera en un infiel, el temido "Turco», peligro muy real cuando se publicó su De civilitate morum puerilium en 1530 (un año después del sitio otomano a Viena): "[Que] se les rindan honras a todos los que honra se les debe, abarcando también la autoridad civil; y si el Turco (no lo quiera Dios) llega a mandar sobre nosotros, hemos de pecar si le negamos a esa autoridad el honor debido". ${ }^{10}$

Ya en pleno siglo XVIII, el discurso de Hervás al respecto del origen y fundamentos del reconocimiento al «honor» y la «dignidad» resulta más ambiguo, pues no llega a precisar si la raíz y justificación de tales jerarquías debe situarse en el «derecho natural» y la «razón natural», por definición normativos, sino que se limita a afirmar que esas y no otras son las costumbres propias y características de la «civilización». Como religioso de inclinaciones ilustradas, a Hervás no se le escapa que las distinciones sociales que hacen a algunas personas merecedoras de especiales atenciones corteses no se inscriben en la naturaleza - que dicta la igualdad entre los humanos - sino que son facticias. Ahora bien, sostiene firmemente que, pese a ello, resultan indispensables para el orden de las sociedades:

A la urbanidad pertenecen de justicia los títulos de honor que, según dicta la razón, o se acostumbra en las naciones civilizadas, se dan a las personas distinguidas por su mérito. Es justo que a cada uno se dé el título que la sociedad le concede por su mérito personal: sin éste la sociedad nos debe mirar tan iguales como nos ha hecho la naturaleza. Los que por su dignidad, que supone siempre el mérito, se aventajan y sobresalen, deben ser distinguidos con títulos característicos de ella (Ibídem: 312).

Hervás no puede dejar de interrogarse por el sentido de las distinciones y jerarquías sociales que justifican los tratamientos de respeto y cortesía. Para él esas distinciones deberían ir asociadas al mérito y las virtudes personales, exigencia que muchas veces no se cumple. ${ }^{11}$ Se muestra así consciente de las ambigüedades propias de los tratamientos de cortesía, cuyos usos sociales en el Antiguo Régimen no eran siempre uniformes ni respondían a una lógica de claridad y transparencia, sino que variaban entre la tratadística y las prácticas, entre las pretensiones individuales de respetabilidad y la posición atribuida por la mirada ajena. Y ello a pesar de que existiera toda una «ciencia» o saber teórico sobre los órdenes sociales y la "calidad» de las personas que pretendía establecer equivalencias precisas entre el rango y los títulos. ${ }^{12}$ Con habilidad, Hervás evita entrar de lleno en un tema espinoso, que obligaría a plantear abiertamente la

10 Erasmo 1985: 67. Un poco más arriba, había declarado: «no se tributan esas honras al hombre, no a los merecimientos, sino a Dios», en referencia a los pasajes del libro de Salomón o de las cartas de San Pablo en las que se ordena el respeto ante las autoridades civiles y religiosas o a la autoridad de los mayores.

11 Con mayor nitidez separaba el teórico francés del siglo XVII Charles Loyseau, en su Traité des ordres et des simples dignités (1613), el "honor externo", consistente en los saludos y los títulos asociados a la dignidad y el rango social, del "honor interno», debido a la virtud personal (citado por Merlin-Kajman 2005: 232).

12 Según Merlin-Kajman (2005), que ha estudiado el caso francés en los siglos XVI y XVII, el saber lexicográfico y la práctica notarial revelan unos hábitos complejos y relativamente flexibles, a veces fruto de una negociación entre las partes implicadas. 
oposición entre virtud individual y jerarquías heredadas. Se limita a reprobar a quienes se muestran en exceso orgullosos de su posición: aquellos que exigen que se les apliquen tratamientos de cortesía pero son renuentes a usarlos con otros; los de "baxo nacimiento», "zelosísimos de que se les den los títulos de honor que, por fortuna de su habilidad o mérito, han logrado»; quienes se hacen otorgar títulos superiores a su verdadera dignidad (pp. 313-314). De ese modo, se hace eco de una larga tradición que en la literatura de cortesía ridiculizaba a quienes se mostraban demasiado susceptibles cuando se omitía con ellos alguna formalidad, y en particular a los plebeyos muy ufanos de lucir los títulos y dignidades recién adquiridos. Ello desde la idea de que la verdadera superioridad no necesita ser exhibida, pues es bien conocida de todos, y es signo de elegancia del superior dispensar al inferior de hacer uso con él de todos los homenajes que le corresponden. Hervás se muestra en este aspecto como un pensador relativamente abierto pero cauto y en última instancia conservador: un jesuita ecléctico que, como otros de sus compañeros de orden (Juan Andrés Morell, Vicente Requeno, Pedro Montengón, Juan Vicente Masdeu, Antonio Conca), supo dialogar con los conceptos y valores de la cultura ilustrada y utilizar para sus propios fines sus medios de comunicación y debate, pero defendiendo en última instancia los principios del orden social de Antiguo Régimen.

Junto al primer nivel de la urbanidad, configurado por imperativos comunes y universales dictados por el instinto sociable de los humanos, y el segundo, cifrado en los principios muy generales que, entre naciones civilizadas, constituyen la «urbanidad a título de justicia» (es decir, las atenciones debidas a la posición social), Hervás distingue un tercer nivel que llama "urbanidad a título de decencia». Este comprende los gestos precisos a observar en las distintas ocasiones sociales, es decir, aquello que los códigos de cortesía tienen de arbitrario y sujeto a la variabilidad y la evolución de las costumbres:

Las acciones de cortesía y urbanidad que son debidas a título de decencia y buena crianza suceden comunmente en el trato ordinario de las gentes, como paseos, visitas, convites y otras ocurrencias. En ésta hay más anchura y libertad, porque por la mayor parte están sujetas a ciertas leyes arbitrarias, que varían al paso que varía el capricho de los legisladores (Ibídem: 317).

En su opinión, estas normas que regulan el trato social en su dimensión cotidiana son contingentes y variables en el tiempo y el espacio, pero igualmente dignas de observancia. Como tantos otros tratadistas sobre urbanidad, aconseja adoptar las convenciones de cortesía propias de la sociedad en la que se vive, siempre con moderación y prudencia, es decir, evitando tanto la afectación excesiva y la obsesión por los formulismos como la ignorancia de aquellos gestos propios de la convivencia social y necesarios para la fluidez de las relaciones: «Negarla del todo [la cortesía] es rústico, y pasar de los límites de la prudencia es hacerse ridículo, pero de todos los extremos es peor el primero que el segundo» (Ídem).

El jesuita dirige palabras satíricas a quienes ponen todo su empeño en observar hasta el mínimo detalle las fórmulas de cortesía, tachándolos de afectados y ridículos: tan ceremoniáticos y escrupulosos, que para no pecar contra los mandamientos del ceremonial, estudian noche y día, reduciéndose a esto todo su saber y ciencia. Con el mismo intento, antes de salir al público, se imponen en su retrete. Allí repiten muchas veces las acciones y palabras de que han de usar en tal concurrencia, tal visita, tal convite, etc.: cómo han de poner la boca, dónde han de poner la mano, cómo han de mover los pies. Si por desgracia caen después en falta, ioh Dios!, les duele más que si hubieran quebrantado un precepto del Decálogo (Ídem).

Sin embargo, es el defecto en la urbanidad y no su exceso lo que le merece un juicio más severo, en tanto que trasluce, a su juicio, falta de respeto hacia los demás:

Se ven algunos que se portan como si cada uno de ellos fuera solo sobre la tierra, y como si no hubiera a quien saludar, a quien descubrir o inclinar la cabeza, ni hacer alguna otra demostración de obsequio. Los ignorantes los tienen a éstos por soberbios y presumidos; los sabios y prudentes los califican de rústicos y necios, y unos y otros tiene razón (Ídem).

Hervás se muestra plenamente consciente de la variabilidad cultural de los usos de cortesía, algo a lo que debían haberle habituado la tradición de los manuales de civilidad, su propia vivencia en el exilio, sus amplias y enciclopédicas lecturas y la experiencia colectiva de sus hermanos de la Compañía como misioneros y mediadores culturales en tierras lejanas. Así, censura a quienes en el transcurso de sus viajes no saben apreciar esa diversidad ni adaptan a ella sus comportamientos, sino que, tomando las propias costumbres como vara de medir, rechazan todo lo que se distancia de ellas: "No es la parte menos considerable de ella [la urbanidad] el tratar a los otros de manera que no se dé a entender que desprecian sus personas o las cosas de sus países. Hay algunos que a qualquiera parte adonde vayan, todo lo desaprueban, todo les parece mal, y no hay en su boca cosa igual a lo que se halla en su país» (Ibídem: 314). Esas últimas palabras recuerdan las del humanista francés Michel de Montaigne (1533-1592), quien tanto en sus ensayos como en el diario de su viaje a Italia ridiculizó a aquellos de sus compatriotas que no encontraban a su gusto nada que se alejara de lo habitual en su tierra materna. Para Montaigne, quienes viajaban con ese espíritu no entendían en absoluto el sentido último del viaje, cuya enseñanza más profunda consiste, precisamente, en deshacerse de los propios prejuicios e ideas preconcebidas para abrir la mente a través de la confrontación con lo ajeno, lo extraño, lo insólito:

A tal efecto -escribía en su ensayo "De la educación de los niños" - es maravillosamente adecuado el conocer hombres, y el visitar países extranjeros, pero no para informarse, según la moda de nuestra nobleza francesa, de cuántos pasos tiene la Santa Rotonda, o de la riqueza de las ropas de la señora Livia; o, como otros, para precisar la mayor longitud o anchura de una efigie de Nerón hallada en una vieja ruina, con respecto a la de alguna semejante medalla. No se ha de viajar para eso, sino para enterarse de los modos y condiciones de los países, y para pulir nuestro cerebro por el contacto con otros (Montaigne 2000: 107-108; cursiva añadida).

Viajero en Italia él mismo, aunque dos siglos después y por motivos distintos a los de Montaigne, Hervás, si bien no compartió el escepticismo del humanista francés, sí fue 
sensible en alguna medida a la riqueza de las diferencias culturales que conoció por sus propias vivencias, sus lecturas y las informaciones proporcionadas por sus contactos.

\section{LAS PALABRAS ¿AMANSAN A LAS FIERAS? LENGUA Y CIVILIZACIÓN}

Sin embargo, el aspecto que más singulariza la aportación de Hervás a la reflexión moral y filosófica sobre la civilidad es su interés por el lenguaje de la cortesía y sus implicaciones. Con una extensión y profundidad inusuales entre los tratadistas sobre el tema, dedica un epígrafe completo del capítulo "Urbanidad y cortesía en el comercio humano» a disertar sobre las relaciones mutuas que guardan entre sí el lenguaje, los hábitos sociales y las actitudes morales. Se trata del epígrafe III, titulado "Observación crítica de las expresiones de cortesía que se usan en los idiomas de las naciones civilizadas", que, no por casualidad, constituye, con diferencia, la parte más extensa del capítulo. ${ }^{13} Y$ también una de las más originales, como él mismo indica al afirmar lo novedoso de su análisis específicamente lingüístico:

He discurrido de las acciones y de los títulos de urbanidad y cortesía, según la idea común; permítaseme que, según la mía, quizá particular, observe y analize las expresiones urbanas y corteses del teatro civil, en que el filósofo crítico puede encontrar causas que conspiren a formar feroz o soberbio, moderado o inhumano el carácter de varias naciones (Hervás 17891799, t. V, cap. IV: 323; cursiva añadida).

Fiel a la inclinación filológica que manifestó en muchas de sus obras (Breva-Claramonte 1991) y mostrando su competencia en la materia, Hervás dedica la parte más extensa de su ensayo a examinar con detalle los tratamientos honoríficos que en distintas naciones se utilizan como signos de respeto. Su objetivo es proponer fórmulas lingüísticas que reflejen debidamente las jerarquías y las dependencias sociales sin incurrir en una inflación artificiosa y vana de las distinciones. Hace uso para ello de sus sólidos conocimientos de lenguas y de gramática comparada, así como de las informaciones y reflexiones proporcionadas por una amplia literatura jesuítica de viajes y descripciones de lugares (relatos de misiones, informes, cartas). Entre ellos concede un lugar central a los países de Extremo Oriente (China, Japón), donde la Compañía era muy activa, y a los territorios italianos, donde él mismo y sus compañeros residían tras la expulsión.

El apabullante despliegue erudito de ejemplos tomados de las lenguas tanto clásicas como modernas, europeas y asiáticas, sean de uso común o minoritarias, le sirve a Hervás para desarrollar una tesis original acerca del poder civilizador del lenguaje. Su planteamiento es complejo y sutil. No se ocupa de denunciar - lo que constituía ya un lugar común en la literatura de urbanidad - la falsedad del lenguaje verbal y no verbal, es decir, de las palabras y los gestos con que se expresa la cortesía y que, en opinión de muchos moralistas, no reflejan verdaderos sentimientos de agrado y consideración hacia los semejantes. Su objetivo es más bien demostrar que la suavidad en las maneras y en los usos verbales puede contribuir a civilizar no solo

13 Este epígrafe ocupa 12 páginas - 323-224- de las 25 totales del capítulo -310-334. las conductas externas, sino también las inclinaciones interiores. De ese modo, en lugar de interrogarse, como hacen otros autores, sobre si el lenguaje trasluce o no en el exterior los sentimientos íntimos, se preocupa por explicar su dimensión productiva: cómo actúa, por así decirlo, desde fuera hacia dentro, contribuyendo a contener y encauzar los afectos e incluso a construir hábitos y sentimientos adecuados. Su planteamiento es en cierta medida clásico, en línea con la convicción, propia de la pedagogía humanista, sobre la capacidad de educar la moral y los afectos interviniendo sobre el gesto y la palabra. Pero también resulta novedoso, pues su detallado análisis comparativo del lenguaje de la cortesía no tiene parangón alguno en otros tratadistas sobre la urbanidad.

En la visión de Hervás, las palabras deben contribuir a generar conductas e inclinaciones adecuadas, tanto a nivel individual, en las personas que las pronuncian, como en las sociedades de las que forman parte, de modo que el lenguaje produce las costumbres a la vez que es producido por ellas, en un juego mutuo:

Las expresiones corteses y urbanas, no los títulos secos de honor, tienen notable influxo para humanizar y amansar la fiereza y soberbia de las naciones poco cultas. La verdadera civilización o cultura no consiste en los títulos pomposos con que se fomentan la altanería y soberbia, como sucede entre muchas naciones orientales, sino en las expresiones corteses de bondad y moderación de quien las dice, y agradecimiento y estimación de otros (Ibídem: 325).

La urbanidad, pues, y cortesía - concluye Hervásse introducen y arraigan en las naciones, tratándose humana y afablemente con expresiones de atención, honor y sumisión, según las circunstancias en que se dicen, y según el carácter de las personas (Ibídem: 324).

En este sentido, explica Hervás, el uso común y habitual de expresiones civiles denotaría la voluntad de contener y regular los comportamientos con el fin de ajustarlos a un ideal de civilización, y por ello esas fórmulas de cortesía deben contemplarse como signos favorables que indican cierto nivel de desarrollo moral y social: "Las locuciones urbanas y corteses que se han introducido en algunos idiomas, y se usan ya como si fueran idiotismos en ellos, son señales de la civil urbanidad que han querido introducir las naciones que los hablan» (Ibídem: 323). Sin embargo, por esa misma razón, las convenciones del lenguaje han de ser mesuradas y no caer en excesos que constriñan y aprisionen a los individuos, restando fluidez a las relaciones sociales: "La lengua cuyas expresiones corteses y cuyo tratamiento cortés se deben empedrar con repetidos y fastidiosos títulos de vuestra excelencia, señoría, etc. no da lugar ni ocasión al desahogo de la humanidad, antes bien tiene a ésta en continua y fastidiosa sujeción» (Ídem).

Hervás vuelve una y otra vez con insistencia sobre la idea central de este epígrafe, la más original de su tratamiento de la cortesía: su convicción de que la lengua, como la música, amansa a las fieras, es decir, contribuye a domar la natural fiereza de los humanos, haciéndolos más atentos y delicados, más moderados no solo en sus expresiones sino en sus mismas costumbres; en suma, más propiamente humanos. Y ello tanto a nivel individual, a través de la tarea pedagógica (que incluye entre sus principales funciones la de enseñar el uso apropiado del lenguaje), como a nivel colectivo, en la 
medida en que define y contribuye a mejorar la civilización de las naciones, formando su carácter «feroz o soberbio, moderado o inhumano» (Ídem).

Para el autor de la Historia de la vida del Hombre, las fórmulas lingüísticas poseen por sí mismas la capacidad de influir en las formas de trato y en la propia configuración de la sociedad. Así, el desarrollo de los signos verbales de cortesía en las distintas lenguas impulsó y precedió -más que limitarse a reflejar - a la mayor complejidad y jerarquización de las relaciones sociales, y su excesiva proliferación tiene por efecto reforzar la rigidez de aquéllas. En el otro extremo, la renuncia a toda distinción y el uso de tratamientos estrictamente igualitarios, como en el caso de las comunidades cuáqueras, le parece irrespetuoso y grosero. El ideal lo constituye, a sus ojos, un modo de hablar franco que, sin omitir el respeto debido a los títulos y dignidades, no abuse de las fórmulas pomposas, introduciendo así en el lenguaje una cierta austeridad y benevolencia que, en virtud del poder de las palabras, acabará comunicándose a las costumbres:

Es necesario persuadirse que la humanidad, afabilidad y casi igualdad en el tratarse destierran la altanería bárbara y la rústica soberbia de las naciones poco cultas. La civilización no consiste en la enfadosa y disonante repetición de excelentísimos, ilustrísimos, vuestra señoría ilustrísima, sino en las expresiones vivamente corteses, atentas y humildes que, por la nobleza del pensamiento y harmonía gramatical de las palabras, hagan en el espíritu y en el oído la debida sensación. Este modo de hablar, que es común al italiano y al francés, se empieza a usar por el inglés (...). Se debe esperar que, haciéndose más común, concurra para hacer más humanas y civilizadas las naciones. ${ }^{14}$

La tesis de Hervás acerca de la formación y evolución de los tratamientos verbales sostiene que en origen, antes de que existiesen títulos de nobleza, las lenguas comenzaron a marcar el respeto a través de las distintas personas verbales y pronombres personales, idea que ilustra con un análisis de estas formas diferenciadas de la segunda persona en una larga lista de idiomas (del "cántabro» y "vizcaíno» al chino, japonés, egipcio, hebreo, turco, griego, armenio, valako, húngaro, inglés, francés o italiano). Reitera su agrado y su preferencia por los hábitos propios de idiomas como el italiano, el francés o el inglés, en los que la cortesía verbal habría abandonado las formas rígidas y extremadamente formales para hacerse más fluida y facilitadora de los intercambios. En lengua inglesa, considera que esos usos han comenzado a extenderse tan solo en tiempos recientes, reconociendo así la variabilidad histórica de los hábitos lingüísticos y, por extensión, de las costumbres, que aquéllos expresan al tiempo que modelan. Por ejemplo, dice preferir los idiomas que no prodigan los tratamientos de cortesía, sino que, tras encabezar la frase con el título correspondiente que indica la dignidad o condición social del interlocutor, prosiguen el

14 Ibídem: 334; la cursiva es mía. Cabe destacar que el uso moderno del término «civilización», distinto a su sentido jurídico anterior, aparece en francés por primera vez en la obra Mirabeau en 1756 y está documentado en español en fecha tan temprana como 1754, en el texto (inédito hasta finales del siglo XIX) de un jesuita, Juan José Delgado, Historia natural sacro-profana, política y natural de las islas del Poniente Ilamadas Filipinas (Fernández Sebastián 2008). discurso sin engorrosas reiteraciones y tratan a todos por igual, como es el caso del latín tu o del francés vous. Se muestra especialmente elogioso hacia los usos contemporáneos del italiano, en los que, según él, los títulos y dignidades, aun respetándose escrupulosamente en la expresión escrita de tipo formal (correspondencia, documentos públicos...), se omiten en la vida cotidiana. Unos hábitos de los que sin duda él mismo tenía una experiencia práctica, como intelectual al servicio de la nobleza italiana, acostumbrado, por tanto, como tantos exjesuitas en su situación (Guasti 2013), a tratar con quienes eran sus superiores sociales y posiblemente satisfecho de que estos, en reconocimiento a su saber y como muestra de confianza, le excusaran de ciertas formas ceremoniosas de marcar y acatar las jerarquías. En su opinión, esa relativa flexibilidad en el uso de los tratamientos facilita el trato y la conversación en los espacios y las ocasiones que brinda la sociabilidad, en las que no es preciso mantener la formalidad de dirigirse a otras personas aludiendo siempre a su condición social a través de un tratamiento de respeto:

No hay nación europea que muestre mayor humanidad en el trato que la italiana: qualquiera persona que, por su nacimiento de meramente noble, o por su empleo civil, o por su literatura, sea admitida en las conversaciones de condes, marqueses, duques y príncipes súbditos, se trata casi como igual a ellos (Ibídem: 333).

Hervás, siempre preciso, no deja de lado el importante matiz de que la igualdad entre gentes de letras y personas de la alta nobleza en los espacios de la sociabilidad cultivada no es completa («casi como igual») y que, en cualquier caso, constituye tan solo una convención útil en el trato o "comercio» social, en la medida en que agiliza las relaciones y las hace más fluidas y amables. No implica, pues, la abolición de las jerarquías, que en todo caso quedan en suspenso, innombradas, en virtud del acuerdo tácito que regula el funcionamiento de la buena sociedad. Cabe ver en ello tal vez una cierta experiencia de las academias y tertulias que abundaban en los territorios italianos, especialmente en la Italia del Norte y en Roma, unas mixtas y otras exclusiva o abrumadoramente masculinas, a las que se refieren los testimonios de numerosos viajeros, incluidos los españoles (Moratín, Pérez Bayer, Azara, Viera, Rodríguez Laso), entre ellos algunos de sus compañeros de orden, como Juan Andrés en sus Cartas familiares. ${ }^{15}$ En esas reuniones de gentes eruditas o distinguidas, era frecuente que los participantes adoptaran apelativos arcádicos (Eraclide Samio, Ersilia, Larisio Dianeo...) que sustituían a sus verdaderos nombres y títulos de nobleza o dignidad, igualándoles simbólicamente bajo una identidad ficticia. Hervás subraya que es a través del trato social, mucho más que del aprendizaje libresco, como esas fórmulas más informales se difunden, modificando con el tiempo las prácticas individuales y, por acumulación, las colectivas ( $\mathrm{A}$ este fin concurren mucho los libros, pero más el trato común, cuyo influxo continuo asegura necesariamente el efecto», Ibídem: 334).

En síntesis, el discurso de Hervás sobre la civilidad integra dos aportaciones originales. De un lado, su concepción del lenguaje como agente de transformación y reforma de

15 Sobre la sociabilidad mixta en Italia en el siglo XVIII, véase Betri y Brambilla 2004. 
las costumbres individuales («el que tiene continuamente en su lengua la humanidad, cortesía y afabilidad, aunque sea de corazón fiero, se hará humano, cortés y afable») y, a través de ellas, de los hábitos colectivos. De otro, y enlazando con lo anterior, su perspectiva evolucionista de la urbanidad, propia de un ilustrado moderado, que la considera universal en sus preceptos esenciales, a la vez que indicativa, en su desarrollo concreto, del grado de civilización de una sociedad.

\section{UNA INSTRUCCIÓN CIVIL EN DOS IDIOMAS: FRANCISCO AZNAR}

Una reflexión menos rica que la de Hervás, pero que también justifica la cortesía como una exigencia universal al tiempo que la declina de forma socialmente diferenciada, es la de otro jesuita expulso mucho menos conocido, Francisco Aznar (1743-1800), acerca de cuya vida apenas disponemos de unos pocos datos, los proporcionados por el erudito y religioso aragonés Félix Latassa y por el propio Hervás en su Biblioteca jesuítico-española (Hervás 2007-2009). Miembro, como este último, de la provincia de Aragón, Aznar vivió en primera persona la experiencia misionera que Hervás conoció a través de sus redes y contactos (Latassa 1802, I: 42-44). Nacido en Palomar (Zaragoza) el 22 de abril de 1745, ingresó en la Compañía el 13 de noviembre de 1761 y marchó en 1764 a América, donde le sorprendió tres años después la orden de expulsión, cuando era escolar en el Colegio de Córdoba de Tucumán, en la provincia jesuítica de Paraguay. Se exilió en Italia, donde fue protegido por el arzobispo de Ferrara, el cardenal Mathei, y donde en 1771 lo encontramos como sacerdote, afincado en Faenza. En Ferrara publicó en 1786 su Instruzione utile alla Gioventù, dedicada al obispo de Eucarpe, Antonio Rossi. ${ }^{16}$ Específicamente orientada a la enseñanza en el seminario de Comacchio (cerca de Ferrara), fundado por el prelado y en el que quizá trabajara él mismo, se adoptó posteriormente como libro de texto en otros seminarios italianos. Es un texto extenso y sobrecargado que combina la ambición erudita con la voluntad de ofrecer una lectura amena, y por ello está atiborrado de citas y de anécdotas heterogéneas, tomadas de las Sagradas Escrituras, los autores clásicos y cristianos, el santoral, los hechos de personajes ilustres o los episodios de la historia reciente.

Aznar se esforzó por acercarse a aquellos políticos y eclesiásticos que podían favorecerle. Tal habilidad en el arte de aproximarse al poder resultó muy útil para la supervivencia de los jesuitas expulsos, pues pocos consiguieron estabilidad y bonanza económica y profesional y la mayoría siguió dependiendo de ayudas económicas recibidas de Madrid: la pensión básica que todos recibían y, en muchos casos, pensiones dobles por los méritos literarios y patrióticos que ellos alegaban (Guasti 2009). En 1790, Aznar tradujo al italiano una carta pastoral del arzobispo de Toledo Francisco Valero y Losa, uno de los que en 1767 se había opuesto a la expulsión de la Compañía, precedida de una introducción («Il traduttore ai leggitori») en la que, además de excusarse por su imperfecto conocimiento del italiano («ho scritto in

16 Aznar 1786. Está compuesta por 12 capítulos, precedidos de una dedicatoria, un prólogo («L'Autore a' Lettori») y una introducción y seguidos por una conclusión, estructura que se mantiene en la traducción castellana. un linguagio non mio»), colmaba de elogios al prelado y su obra (Aznar 1790).

Más de una década despues de que su Istruzione utile alla gioventù viese la luz en italiano, Aznar se propuso publicarla también en castellano, estrategia frecuente entre los exjesuitas que buscaban así hacer méritos desde el exilio o tras el retorno a España. Con esa intención redactó un pulcro manuscrito de 400 páginas, que acabó de copiar el 3 de agosto de 1798, pocos meses después del decreto que permitió el regreso de los expulsos, y que dirigió a Floridablanca, ministro de Gracia y Justicia (Aznar 1798). La iniciativa le valió la concesión de una pensión doble, que el también jesuita P. Luengo consideró injustificada por el poco mérito del libro y que atribuyó a la habilidad de su autor para granjearse el favor de personajes poderosos, en particular de su paisano Azara. ${ }^{17}$ El texto castellano, del que se conserva un ejemplar manuscrito en la Biblioteca Histórica de la Universitat de Valencia, nunca llegó a publicarse y jamás, hasta donde yo pueda saber, ha sido estudiado.

Según su autor, la versión española constituía una obra sustancialmente distinta de la edición italiana, aunque en realidad las diferencias son más bien de detalle, como se aprecia al compararlas. La dedicatoria al obispo de Eucarpe se sustituye por una genérica "A la juventud española», y aunque se mantiene el contenido, se presenta como un texto dirigido más ampliamente a los jóvenes varones de cierta distinción, especialmente a los alumnos de seminarios y otras instituciones educativas, en lugar de a los escolares del establecimiento concreto para el que fue concebida. El prólogo a los lectores españoles subraya, en mayor medida que el italiano, la dimensión moral y cristiana de la cortesía, aclaración que el mismo autor consideró necesaria. Algunas de las muchas anécdotas que sazonan el texto son distintas de las contenidas en la edición italiana: se suprimen historias que resultarían irrelevantes para los lectores españoles y otras que, aunque divirtiesen al público italiano, podrían considerarse inadecuadas por incidir en el tópico del carácter orgulloso de los españoles, muy arraigado en Italia desde los tiempos del dominio hispánico en el Sur de la península: entre ellos las anécdotas de dos damas nobles barcelonesas que llevan a los tribunales una disputa sobre a cuál de ellas le corresponde ceder el paso a otra con su carruaje, o la de un noble castellano muerto en un duelo sobre cuestiones igualmente de etiqueta y precedencia (Aznar 1786: 135, 164-165). Añade, en cambio, alguna anécdota sobre el viaje

17 «Entre los cinco que nuevamente han recibido el premio de segunda pensión [...], el segundo es Francisco Aznar, aragonés de nación, y jesuita de la provincia del Paraguay. Ha dado a luz un librito sobre la educación, que no he visto ni he tenido empeño de ver. Pero he oído a los que pudieran tener algún interés en alabarle, que es cosa ordinaria y aun miserable, y se asombran de que se le haya dado el dicho premio. Pero él se habrá ingeniado bien y habrá buscado verosímilmente la protección del Sr. Azara, y a este Ministro, yendo delante el título de aragonés, poco mérito en el Autor le habrá bastado para recomendarle con eficacia a la Corte». Manuel Luengo, Diario de la expulsión de los jesuitas de España, Archivo Histórico de Loyola, tomo XXI, 19 de diciembre de 1787, ff. 625-626. Agradezco esta referencia a los profesores Enrique Giménez e Inmaculada Fernández de Arrillaga; sobre Luengo, véase Fernández de Arrillaga 2002. Más apreciativo se muestra el sacerdote y erudito aragonés Félix Latassa y Ortín: «Esta traducción no ha salido en Español, y quizá se hallará en el Archivo secreto de aquel Señor Ministro, hasta que dé en manos que conozca [sic] su mérito, y el aprecio que se merece, y la dé a luz pública» (Latassa 1802, VI: 44). 
de Carlos de Borbón, rey de Nápoles, a Madrid, pasando por Barcelona, para ser coronado como rey de España en 1759.

Como era de prever, el autor, que en el texto italiano se expresaba en primera persona acerca de las costumbres de aquellos territorios, mimetizándose con el entorno y sin ninguna referencia a su origen, pasa a escribir en castellano identificándose con lo español. Además, en una pequeña pero significativa adaptación, suprime la referencia a las mujeres (junto a los labriegos y artesanos) como ejemplo de personas en quienes serían comprensibles conversaciones banales, impropias, en cambio, de la dignidad de los jóvenes nobles. Quizá porque esperaba o deseaba que su texto, una vez publicado en España y aun dirigiéndose preferentemente a lectores varones, fuese acogido también por un público más amplio que incluyese a mujeres interesadas en conocer las reglas de la educación civil y cristiana (o a los progenitores que quisieran adaptarlas para ellas), por lo que no le convenía ofender a posibles lectoras. Donde el texto italiano sentencia: "Che i contadini, e bisolchi, che gli artigiani, e le donne, parlino di cose da nulla, o al più di quelle lor faccende, non v'ha che dire», el castellano reza así:

Que el vulgo hable de cosas de poca monta, que el mercader hable de sus ganancias, el labrador de sus labores y cosechas, y el pastor de su rebaño, es cosa natural y no hay nada que decir, pues es su ocupación y su objeto (...). Pero que personas civiles y de estimación, que jóvenes nobles y dotados de la naturaleza de ingenio perspicaz e índole generosa quieran entretenerse en discursos vanos e inútiles, es abuso digno de gran vituperio, y debéis procurar estar lejos de caer en él (Aznar 1786: 107; 100, cap. 6: sin paginación).

En suma, la versión castellana difiere mucho menos de la italiana de lo que su autor, buscando subrayar el mérito de su trabajo, pretendió, y aparece más bien como una traducción interesada, oportunista y probablemente rápida. Sin embargo, resulta interesante porque trasluce una voluntad no solo de congraciarse con el gobierno español, presentándose como útil para sus propósitos de reforma educativa y de las costumbres, sino también de llegar —al menos en potencia - a públicos distintos del que tuvo en mente al escribir el original italiano, que tenía unos destinatarios más concretos y homogéneos, los jóvenes seminaristas de Comacchio. Aunque podamos especular con que Aznar acariciase la idea de alcanzar a lectores e incluso lectoras de variada condición, los cierto es que el modelo que perfilan sus consejos es el del joven varón civil y cristiano, destinado por su nacimiento y educación a ocupar responsabilidades en la administración de la monarquía o en la jerarquía eclesiástica. Aznar presenta su Instrucción como un texto dirigido en especial a esa juventud masculina y elitista, a la que exhorta a convertirse, por la discreción y compostura en su conducta, en modelo de civilidad y buenas costumbres, honrando así la educación recibida y contribuyendo a la utilidad pública. Lo hace adoptando una postura de patriota que pretende preservar el "carácter nacional» español, marcado por una digna gravedad, al tiempo que dotarlo del barniz cortés y sociable apropiado para los nuevos tiempos:

Escrivo para la juventud de una nación que, sin exterioridades afectadas y postizas, sabe acompañar con su natural gravedad un trato honrado y cortés. Escrivo para los alumnos de los colegos y seminarios donde está recogida la flor de la misma juventud a fin de recibir una cultura más especial, la qual ninguna cosa desea sino enriquecer su mente con todo género de doctrina y hermosear su alma con tod género de virtud, y comparecer en el trato y exterior porte de su persona como conviene, adornada de una gravedad modesta y de una modestia grave, sociable, atenta y cortés, afable en sus palabras, en su conversación discreta, en sus acciones moderada, y en todo su exterior compuesta, sin cosa alguna que pueda ofender o dar en rostro a ninguno, de manera que el solo verla y tratarla sirva a todos de prueba convincente de la excelente educación de nuestros seminarios (Aznar 1798, cap. 1: sin paginación).

A diferencia de la obra de Hervás, que justifica la civilidad desde argumentos filosóficos y morales más que religiosos, el texto de Aznar se inserta con nitidez, desde su propio título hasta su justificación y al contenido de sus preceptos, en la tradición de la urbanidad cristiana, que se esfuerza por comparar la cortesía con las virtudes piadosas. Se trata de una tradición que tuvo su más célebre ejemplo en las Règles du décorum et de la civilité chrétienne (1703) de Jean-Baptiste de La Salle, pero también en otros textos de autores jesuitas. En efecto, los miembros de la Compañía, junto con los escolapios, se habían significado en la producción de textos de civilidad, como parte de su actividad pedagógica Como ha señalado Inge Botteri: «la buena crianza, entendida como una particular forma de sociabilidad que connotaba el comportamiento y las relaciones sociales, se convierte en un medio necesario para todo tipo de instituto; sería casi imposible separar la conversión de la conversación, la fe de las obras cotidianas, el amor a Dios y al prójimo de lo que se consideraba socialmente como bueno" (Botteri 1999: 145-146). ${ }^{18}$ Así lo expresaba la divisa de buona vita, buona dottrina e buona creanza propuesta en 1572 para el Collegium Germanicum.

Jesuita fue Giovanni della Casa, autor del Galateo (1558), célebre obra de la que se hicieron numerosas ediciones, traducciones y adaptaciones (Della Casa 2003) y cuya versión castellana, el Galateo español de Lucas Gracián Dantisco, se reeditó incesantemente desde su aparición en 1582, con al menos siete ediciones tan solo a lo largo del siglo XVIII (Gracián Dantisco 1968). Jesuita fue el autor de una Instrucción de Christiana, y Política Cortesanía con Dios y con los hombres, Antonio Codorniu, que la publicó en 1740 bajo el pseudónimo de Fausto Agustín de Buendía para el uso del Colegio Imperial de Cordelles. En los territorios vascos, como muestran los estudios de Javier Esteban, los jesuitas produjeron una amplia literatura «civilizadora», de carácter moral y pedagógico, en lengua autóctona y orientada a la formación de las elites locales (de cuyas propias filas procedían en su mayoría los jesuitas, bien conectados tanto en el propio territorio vasco como en la Corte) y a la instrucción en las escuelas de primeras letras; el único manual de cortesía conocido en euskera, el inédito Cristavaren cortesia, fue obra de un jesuita no identificado. ${ }^{19} \mathrm{Al}$ mismo tiempo, como confesores

18 «[L]a creanza, intesa como una particolare forma di sociabilità connotante il comportamento e i rapporti social, divenne un necesario médium per ogni tipo di instituto, quasi fosse impossibile scindere la conversione dalla conversazione, la fede dalle opere quotidiane, l'amore di Dio e per il prossimo da quanto era socialmente reputato buono» (Botteri 1999: 145-146).

19 Esteban Ochoa de Eribe 2017 y 2018. 
de nobles de ambos sexos, como teólogos morales y como educadores, muchos jesuitas adoptaron el probabilismo y sostuvieron que los preceptos morales podían adaptarse a las circunstancias, ajustando así la moral cristiana a los requerimientos de la vida en sociedad..$^{20}$

Bebiendo de esas tradiciones, tomando como modelo la obra de S. Clemente de Alejandría El Pedagogo y apoyándose también en la autoridad de otros autores cristianos, Aznar argumenta que el creyente debe adornar la virtud y la fe con las cualidades del buen trato, el agrado y la suavidad de los modales. En el siglo XVIII muchas eran las sospechas que recaían sobre la civilidad, desde un sentido religioso de rechazo a las vanidades externas o bien en nombre de la crítica moral y utilitaria a los valores y prácticas educativas de Antiguo Régimen. Consciente de ello, el exjesuita justifica la urbanidad como proyección y ornamento de las virtudes del ánimo (idea que, como hemos visto, remacha todavía más en el prólogo castellano) y construye un discurso que establece continuamente nexos entre civilidad y moralidad: «en una instrucción sobre la urbanidad y cortesía puede muy bien entrar la moral e interior cultura del ánimo»; "con el motivo de enseñar a los jóvenes el buen término y cortesía, [podré] insinuarles algunas máximas morales y el amor a la virtud, persuadiéndoles su práctica, sin la qual toda la exterior cultura y urbanidad no sería sino un exterior y lustroso varniz dado a una mala loza» («Prólogo al lector», sin paginar). Los ejemplos de compostura y buena conducta que se ofrecen a los jóvenes y los referentes textuales (clásicos grecorromanos y cristianos, pero sobre todo textos bíblicos, en especial del Eclesiástico y los Proverbios) contienen una fuerte impronta religiosa, que se aprecia también en el lenguaje y los argumentos, por ejemplo en el uso ocasional de los símiles del pecado y el castigo, aplicados a las faltas contra la urbanidad y sus consecuencias, en los argumentos providencialistas (como el que sostiene que Dios creó un mundo en el que el agua abunda más que las vides para fomentar la temperancia) o en las censuras morales aplicadas a la bebida y la conducta en la mesa. ${ }^{21}$

Aznar sustenta la urbanidad en la inclinación hacia el trato con el prójimo, inscrita en la naturaleza humana por designio divino:

Si los hombres pudiesen vivir lejos del comercio humano y de la sociedad civil, no sería necesaria la práctica de aquella policía y urbanidad de la qual entro a tratar. Pero siendo su vida, por instinto de naturaleza y por disposición de la Providencia, enderezada no sólo al particular bien de cada uno, sino también a la utilidad de todos los demás, en quanto es indispensable el vivir juntos y tratar entre sí continuamente, se hace $\tan$ necesaria que sin ella sería ciertamente enfadoso

20 Sobre el papel del catolicismo mundano en la justificación y consolidación de la sociabilidad elitista en los territorios católicos, véase Anastácio (2010). Hubo también, no obstante, jesuitas rigoristas, que clamaron con gran dureza contra las nuevas formas de sociabilidad y ocio propias del siglo (teatros, tertulias y reuniones mixtas), como ilustran, por ejemplo, sus conflictos con la Sociedad Bascongada de los Amigos del País (Esteban 2018).

21 Aznar 1798, capítulos 1 ("Quánto desdoro causa la falta de urbanidad en una persona») y 100 ("De la moderación que se ha de usar en la bebida»), en el que se encarece el uso moderado del vino y se reprueban los gastos excesivos en la mesa en nombre de la caridad cristiana hacia los pobres. y molesto el trato humano. [...] La naturaleza humana, sociable en el común de los hombres, ninguna cosa apetece tanto como la conversación y el trato (Aznar 1798, cap. 1: sin paginación).

Esa tendencia natural a la relación con los semejantes es para Aznar el origen de la organización política y, en última instancia, el cemento de la sociedad. Haciéndose eco de un tópico humanista que cobró nueva fuerza en el siglo XVIII, afirma que quienes ignoran o rechazan los principios más básicos de la cortesía no merecen ser tenidos por propiamente humanos: «Faltándole la policía y buen modo en el trato, [la persona] pierde, por decirlo assí, la mitad de sí misma, y es más a propósito para habitar en los bosques y selvas, en compañía de los árboles y fieras, que para vivir entre los hombres» (Aznar 1798, «Introducción»: sin paginar).

En ese sentido, toma partido en los debates del siglo XVIII sobre la esencia moral de la "policía y urbanidad» y, frente a las críticas que sospechan de su frivolidad o hipocresía, la defiende no solo como una obligación cristiana sino como un ingrediente esencial para construir y fortalecer los vínculos sociales y suavizar el trato humano, reduciendo los conflictos al minimizar los motivos de roce o agresión.

Así, el triple eje que articula el discurso de Aznar sobre las conductas y que se reitera, en combinaciones variables, en cada uno de los capítulos de su obra lo constituyen las exigencias de la modestia como guía del comportamiento del cristiano, la distinción a través de la apariencia y el comportamiento y la fluidez y suavidad del trato social. El joven varón noble que se perfila como destinatario del texto debe ser modesto y decoroso en sus palabras, en sus acciones y en la custodia de sus sentidos, respetuoso con sus superiores (padres, parientes, maestros y sacerdotes), humilde y considerado en la convivencia con sus compañeros (cap. 3), caritativo en el trato con sus inferiores (cap. 4), compuesto en su vestido, su porte y sus gestos (cap. 5). La necesidad de cuidar el aspecto personal aparece como un requisito general de la convivencia: «Quien desee vivir como hombre racional y civil entre sus semejantes, debe procurar formarse a norma de las reglas de urbanidad y policía, exercitándose y creciendo cada día en cultura y propiedad, y en el aseo de su persona» (cap. 5). Pero también como una imposición particular de la "señoril educación», es decir, de quienes deben acreditar en su porte externo la dignidad de su cargo o su nacimiento. Los extremos que Aznar exhorta a evitar en el propio atuendo y presentación de sí son, de un lado, la negligencia y, de otro, la excesiva compostura. Esos defectos remiten a los principios generales que, en este como en otros aspectos, marcan los límites del comportamiento civil, cuya regla de oro consiste en huir de toda disonancia con las convenciones de la sociedad, sea por descuido o por afectación excesiva, «de manera que nada haya de extravagante o de incivil, ni por el contrario de afectada composición y sobrado estudio, porque lo primero arguye un genio tosco y desaliñado, y lo segundo un ánimo vano y demasiadamente delicado» (cap. 5).

Los referentes negativos, es decir, aquellas faltas que se deben evitar en el comportamiento, se identifican recurrentemente en el texto de Aznar con la rusticidad y tosquedad: el "andar pastoril», el "porte sin decoro» del "vulgo» y de las gentes sin educación, frente a las maneras 
propias de «personas civiles». Se hace explícito así a cada paso el carácter selectivo y excluyente que tiene su propuesta pedagógica. Advertencias y preceptos revisten un carácter particularmente minucioso: Aznar no rehuye la crudeza explícita para censurar las infracciones a los buenos modales en la mesa, recordando que es inadmisible eructar, limpiarse los dientes o enjuagarse la boca en presencia de otros. Ese lenguaje directo, más que basarse en los malos vicios detectados en los jóvenes a partir de su experiencia particular como educador, recuerda el de otros tratados célebres de urbanidad, como el De civilitate morum puerilium (1530) de Erasmo y tantos otros en su estela, que pudo conocer e imitar.

De todos los escenarios y prácticas del comportamiento civil abordados en la obra de Aznar, el que recibe un tratamiento más detenido es la conversación. Le consagra tres capítulos (6 al 8), en los que puede apreciarse con nitidez su carácter central en el discurso sobre la civilidad, así como las normas que deben regularla. Siguiendo la tradición de la Civil conversazione (1574) de Stefano Guazzo, así como la del pensamiento francés del siglo XVII sobre la honnêteté y la politesse, Aznar entiende la conversación en un sentido amplio, no solo como un intercambio verbal, sino como símbolo y lugar privilegiado del trato social. El don de la palabra - argumenta - es lo que distingue a los humanos de los animales, pero no es cualquier conversación, sino aquella establecida entre "gente dezente, culta y civil», lo que constituye un intercambio enriquecedor que permite aprender escuchando a los otros y acomodando el propio uso de la palabra a las reglas que dicta el intercambio social. De acuerdo con el uso, muy extendido en el siglo XVIII en diversas lenguas europeas, que asimilaba bajo el mismo término de "comercio» tanto las transacciones económicas como el trato social (por ejemplo, "comercio entre los sexos» como sinónimo de relaciones mixtas), Aznar compara la conversación con "los mercados públicos, en los quales llevando cada uno lo que tiene, y comprando de lo que no tiene, todos quedan provistos de lo que necesitan y, sin perder lo propio, adquieren lo ageno» (Aznar 1798, cap. 6: sin paginación; cita atribuida a Daniel Zart).

Entendida así, la conversación constituye un arte que requiere un cuidadoso aprendizaje, para el que resulta necesario conocer de forma sólida las materias que se tratan, pero también y sobre todo dominar la palabra y el gesto, el tono de voz, la velocidad, ritmo y duración del discurso, así como evitar la mentira, la exageración, la doblez y la murmuración, la inmodestia y la frivolidad. Hay que procurar que los temas de conversación sean instructivos y decorosos, que hagan honor a la cultura, distinción y buenas costumbres de los interlocutores, sin abordar asuntos excesivamente bajos y vulgares o bien, por lo contrario, tan especializados o eruditos que puedan excluir a algunos de los participantes (Ídem).

La regla de oro en la conversación, y por extensión en el trato con los demás, es el arte de procurar un intercambio fluido y agradable. Entendido como acto social, el diálogo nunca debe convertirse en monólogo, lo que obliga a evitar todo aquello que pueda desagradar a los demás, a acomodar los temas y el tono de la conversación a los gustos y capacidades de los interlocutores, a ejercer las habilidades de callar, escuchar y preguntar, a ceder la palabra y procurar conciliar los pareceres adversos, sin empecinarse en la contradicción. En definitiva, más que un arte de distinguirse en el uso brillante de la palabra y la réplica ingeniosa, es una disciplina del ajuste y la armonía, que exige eclipsarse voluntariamente y evitar todo gesto para el propio lucimiento. De ahí la dureza con que se expresa Aznar contra quienes en lugar de ello se esfuerzan en convertirse en centro de atención para exhibir su saber: «llenos de sí mismos, y ufanos con la presunción de saber quanto hay que saber, se imaginan que son una librería portátil».

La Instrucción útil para la juventud se presenta, pues, ampliamente deudora de la literatura anterior de civilidad, en particular la de espíritu y referentes religiosos, pero también de la tradición laica, renacentista y barroca, de la cortesía. No obstante, algunos matices más contemporáneos denotan su enraizamiento en la cultura del siglo XVIII. En primer lugar y como hemos visto, su lenguaje adopta en algunos pasajes, muy especialmente en la dedicatoria de la versión castellana, el tono utilitarista y patriótico del reformismo ilustrado. En segundo lugar, sus consejos sobre el arte de la conversación participan de la crítica, tan característica del siglo XVIII, contra las nuevas tendencias divulgativas propias de la cultura de la llustración, personificadas en la sátira contra el «hombre universal», el «literato a la moda» o lo que Cadalso llamaría "erudito a la violeta», al que Aznar contrapone el estudio serio y sistemático. Por último, los capítulos dedicados al juego y los ejercicios se mueven entre el tradicionalismo y la modernidad. De un lado, insisten (como toda la literatura de civilidad de carácter más intensamente pedagógico) en el decoro y la modestia que deben regir la conducta del joven cristiano y civil en todo momento, incluso durante los esparcimientos del juego o el paseo. De otro, muestran un interés por los beneficios del ejercicio y su imperativa necesidad en los establecimientos de educación que conecta no solo con la tradición pedagógica jesuítica, en la que siempre se había reservado un espacio a la educación y disciplina del cuerpo, sino también con las preocupaciones higienistas del siglo XVIII y con la creciente importancia que en la pedagogía más actualizada se concedía a la actividad física, de la que son ejemplo obras tan distintas como el Émile (1762) de Rousseau y el Discurso sobre la educación física y moral de las mujeres (1790) de Josefa Amar.

Los argumentos médicos sobre los males de la vida sedentaria y los efectos saludables del movimiento se acompañan en la Instrucción de referencias a Simon-André Tissot («el señor Tissot, médico suizo acreditado por las muchas obras que ha dado a luz»), cuyos consejos para la salud, traducidos en varias lenguas (entre ellas el italiano y el castellano), corrieron por toda Europa. ${ }^{22}$ Los comentarios de Aznar son reveladores de la difusión de estas ideas a finales del siglo XVIII entre las élites europeas, lectoras entusiastas de la literatura médica de divulgación y defensoras de sus principios. En sus largos años en Italia dice haber apreciado cómo practicar ejercicio de forma regular se había convertido en un hábito cotidiano entre gran parte de la población (se supone que acomodada o de medianos recursos), como

22 Tratado de las enfermedades más frecuentes de las gentes del campo (1774), Avisos a los literatos acerca de su salud (1786). Sobre Tissot y los tratados médicos de divulgación en el siglo XVIII, véanse Perdiguero 2003 y Bolufer 2000. 
supuesta herencia de la tradición clásica, a lo que atribuye la longevidad superior a la europea de que, en su opinión, se gozaba en aquel territorio. En el texto original, alaba esa saludable práctica usando la primera persona del plural para identificarse con los italianos ("a dì nostri» o "della nostra Italia»); en la versión castellana, la presenta como todavía ajena a los usos españoles, refiriéndose en este caso a los italianos en tercera persona ( «il far moto, como ellos dicen»). ${ }^{23}$ Se adscribe así a las preocupaciones características del higienismo, que entendía implícitamente la salud como una forma de distinción social y moral, y aboga por extender a España una admirable costumbre que considera más arraigada en la península italiana.

El lugar común acerca del carácter variable de las costumbres no está ausente en otros pasajes de su texto, en los que, tras contrastar los usos habituales de distintos países en alguna circunstancia precisa, recuerda la necesidad de observar las diferencias para adaptarse a ellas:

Esta regla general abraza mucha doctrina y y se extiende a todos aquellos puntos que, por ser variables según el genio de diversas naciones, no se pueden reducir a un determinado método, sino que es necesario tomar la norma de la policía y urbanidad y del uso introducidos respectivamente entre ellos.

Finalmente siendo vario el genio y modo de obrar de las diversas Naciones, qualesquiera persona civil y que quiera [destacar?] debe informarse de las costumbres y estilos que tienen en la Región en que reside y circunstancias en que se hallare (Aznar 1798: caps. 10 y 9: sin paginación; 1786: 143 y 138).

Para ejemplificar esas variaciones, Aznar recurre preferentemente a los clásicos grecorromanos y los autores cristianos del pasado que permiten apreciarlas a través del tiempo, pero también aporta algunos detalles tomados - probablemente, pues no indica sus fuentes - de los textos jesuíticos sobre misiones en territorios orientales y - solo en pocas ocasiones- de su propia experiencia en América. Si consigna como mera curiosidad que los japoneses comen en mesas bajas, sentados sobre sus talones, utiliza, más significativamente, el ejemplo de «los nuevos christianos del Paraguai», entre quienes vivió tres años él mismo, para aleccionar a sus lectores en la necesidad de desplegar en la mesa no solo buenos modales, sino también una actitud piadosa. $^{24}$

\section{A MODO DE CONCLUSIÓN}

Aznar y Hervás utilizaron su experiencia como educadores de varones nobles en Italia y su amplio bagaje de noticias sobre las misiones americanas o asiáticas de la Compañía de Jesús para ofrecer al público español el producto de sus reflexiones y propuestas pedagógicas, que ya habían dado

23 «Non è minore a' dì nostri l'uso, e la stima del moto di quello fosse apresso gli antichi, parlando singolarmente della nostra Italia» (Aznar 1786: 157; Aznar 1798, cap. 11: sin paginación).

24 «Los nuevos christianos del Paraguai e imitadores verdaderos de esos primeros fieles en la santidad de vida no se contentan con bendecir sus mesas frugales y dar gracias al Señor después de aver comido, sino que además de eso acostumbran poner sobre las mismas durante la comida una pequeña estatua de algún santo protector» (Aznar 1798, cap. 10: sin paginar; Aznar 1786: 143 y 152). a conocer en el ámbito italiano años antes. Ambos adaptaron sus obras para publicarlas en España: por imposición de la censura, en un caso; por interés en congraciarse con las autoridades, en otro, pero también, en ambos, desde la conciencia de que las costumbres resultaban parcialmente distintas en un país y en otro y que por ello su escritura debía amoldarse al nuevo contexto de recepción. En sus reflexiones, la cortesía aparece como una moneda de cambio universal que permite conectar con aquellos en alguna medida extraños o radicalmente exóticos, pero al mismo tiempo como un arte que admite infinitas variaciones, reveladoras no solo del grado de dominio personal de la civilidad, sino de la superioridad o inferioridad relativa de las distintas sociedades. Apoyándose en la trayectoria misionera y educativa de su orden y en su propia vivencia personal del exilio, estos exjesuitas manifestaron curiosidad e interés por las costumbres y las formas de cortesía más allá de las fronteras de Europa, interrogándose así sobre su carácter universal o específico y sobre el sentido de las diferencias culturales que a través de ellas se expresaban.

Se trata, ciertamente, de dos textos y dos autores muy distintos. Mientras que la Historia de la vida del Hombre de Hervás es un tratado teórico y filosófico de gran altura, obra de un intelectual de prestigio en la república de las letras, con amplio influjo en el grupo de los jesuitas expulsos, la Instrucción civil y cristiana de Aznar, desconocida hasta ahora en su versión castellana, es un libro de mucho menor vuelo, un manual educativo con propósitos más concretos y modestos, fruto de la pluma de un autor de segunda fila. Sin embargo, el estudio comparado de ambos permite corroborar la fertilidad del exilio italiano como ámbito de reflexión y conexiones intelectuales entre los jesuitas expulsos y las estrategias de estos para abrirse camino a su vuelta a España. Permite también apreciar la importancia de los saberes aportados por los misioneros en América y Asia a los debates culturales del siglo XVIII: entre otros, y tal como he puesto de relieve en estas páginas, el sostenido a propósito de la naturaleza, origen y justificación moral de la urbanidad. Tanto la brillante reflexión de Hervás como las disquisiciones, más mediocres, de Aznar, revelan un interés por dar cuenta de la amplia variación cultural de las costumbres en los distintos lugares del globo y por interrogarse por su sentido y su racionalidad específica. Al mismo tiempo, no obstante, muestran un sostenido esfuerzo por defender el carácter universal de las normas fundamentales de comportamiento humano (de las que la urbanidad sería un ejemplo), así como su íntima conexión, en última instancia, con la moral cristiana, frente a las derivaciones relativistas de la Ilustración más radical.

\section{FUENTES}

Anónimo. 1807. Lecciones de urbanidad, destinadas a servir de suplemento al Silabario ortológico de la parroquia de Santa Eugenia de Fao, extractadas de varios autores. Santiago: Juan Francisco Montero y Frayz.

Aznar, Francesco. 1786. Istruzione utile alla gioventù per regolare se stessa nella vita civile, e morale Cristiana. Ferrara: Eredi di Giuseppe Rinaldi.

Aznar, Francesco. 1790. Lettera pastorale dell'illmo. e revmo. Mons. Dn. Francisco Valerio e Lossa, arcivescovo de Toledo, nella quale manifesta a tuii i suoi sudditti i motivi, che vi sono di temeré, che l'ignoranza della verità cristiane sia raggione di quello si crede 
etc. Tradotta dall'idioma espagnuolo del sacerdote Dn. Francisco Aznar. Ferrara: Francesco Pomatelli.

Aznar, Francisco. 1798. Instrucción util a la juventud para su govierno en la vida civil, moral, christiana. Compuesta por el presbítero Don ... el qual la consagra a la juventud española. Valencia: Biblioteca Històrica de la Universitat de València, Mss. 541.

Della Casa, Giovanni. 2003. Galateo, ed. y trad. de Anna Giordano y Cesáreo Calvo. Madrid: Cátedra.

Erasmo, Desiderius. 1985. De la urbanidad en las maneras de los niños [De civilitate morum puerilium], ed. bilingüe, traducción y presentación de Agustín García Calvo, edición y comentario de Julia Varela. Madrid: Ediciones de la Piqueta.

Gracián Dantisco, Lucas. 1968. Galateo español, estudio preliminar, edición, notas y glosario de Margherita Morreale. Madrid: Consejo Superior de Investigaciones Científicas.

Hervás y Panduro, Lorenzo. 1789-1799. Historia de la vida del Hombre. Madrid: Imprenta del Real Arbitrio de la Beneficencia, 7 vols.

Hervás y Panduro, Lorenzo. 2007-2009. Biblioteca jesuítico-española, estudio introductorio, edición crítica y notas de Antonio Astorgano Abajo. Madrid: Libris.

Latassa y Ortín, Félix. 1802. Biblioteca nueva de los escritores aragoneses que florecieron desde el año de 1795 hasta el de 1802 Pamplona: Oficina de Joaquín Domingo.

Montaigne, Michel de. 2000. «De la educación de los niños», en Ensayos completos, vol. I: 101-130. Barcelona, Ediciones Folio.

Requeno y Vives, Vicente. 2008. Ensayos filosóficos, edición de Antonio Astorgano Abajo. Zaragoza: Prensas Universitarias de Zaragoza / Instituto de Estudios Altoaragoneses / Instituto de Estudios Turolenses / Dept. de Educación, Cultura y Deporte del Gobierno de Aragón.

\section{BiBLIOGRAFÍA}

Anastácio, Vanda. 2010. "Women and literary sociability in eighteenthcentury Lisbon», en Anke Gilleir, Alicia C. Montoya y Suzan Van Dijk (eds.), Women Writing Back/Writing Back Women: 93-111. Leiden: Brill (colección Intersections 16).

Astorgano Abajo, Antonio. 2010. Lorenzo Hervás y Panduro (17351809), sabio polígrafo. Toledo: Almud Ediciones.

Batllori, Miquel. 1966. La cultura hispanoitaliana de los jesuitas expulsos: españoles, hispanoamericanos, filipinos (1767-1814). Madrid: Gredos.

Betri, Maria Luisa y Elena Brambilla (coords.). 2004. Salotti e ruolo femminile in Italia tra fine Seicento e primo Novecento. Venecia: Marsilio.

Bolufer, Mónica. 2000. "Ciencia de la salud y ciencia de las costumbres: higienismo y educación en el siglo XVIII». Áreas. Revista de Ciencias Sociales 20: 25-50.

Bolufer, Mónica. 2019. Arte y artificio de la vida en común. Los modelos de comportamiento y sus tensiones en el Siglo de las Luces. Madrid: Marcial Pons.

Botteri, Inge. 1999. Galateo e galatei. La creanza e la istituzione della società nella trattatistica tra antico regime e società liberale. Roma: Bulzoni.

Botteri, Inge. 2004. "Buona vita, buona dottrina e buona creanza": i Gesuiti e il galateo», en Manfred Hinz, Roberto Righi y Danilo Zardin (eds.), I Gesuiti e la Ratio Studiorum: 21-41. Roma: Bulzoni.

Breva-Claramonte, Manuel. 1991. "Las ideas lingüísticas del siglo XVIII en Lorenzo Hervás: la descripción de las lenguas del mundo». Anuario del Seminario de Filología Vasca "Julio de Urquijo» (ASJU): International Journal of Basque Linguistics and Philology 25 (3): 769-791.

Brotton, Jerry. 2003. El bazar del Renacimiento: sobre la influencia de Oriente en la cultura occidental. Barcelona: Paidós.

Burke, Peter. 2007. "The Jesuits and the Art of Translation in Early Modern Europe», en John W. O'Malley, Gauvin Alexander Bailey, Steven J. Harris y T. Frank Kenney (eds.), The Jesuits. II. Cultures, Sciences, and the Arts, 1540-1773: 24-32. Toronto: University of Toronto Press.
Cañizares-Esguerra, Jorge. 2007. Cómo escribir la historia del Nuevo Mundo: historiografías, epistemologías e identidades en el mundo del Atlántico del siglo XVIII. México: Fondo de Cultura Económica.

Diz, Alejandro. 2000. Idea de Europa en la España del siglo XVIII. Madrid: BOE.

Esteban Ochoa de Eribe, Javier. 2017. «Cristavaren cortesia. Las fuentes hispánicas de un manual de urbanidad en euskera». Investigaciones Históricas. Época Moderna y Contemporánea 37: 271-295. https:// doi.org/10.24197/ihemc.37.2017.271-295

Esteban Ochoa de Eribe, Javier. 2018. Discursos civilizadores. Escritores, lectores y lecturas de textos en euskera (c. 1767-c.1833). Madrid: Sílex.

Fernández de Arrillaga, Inmaculada. 2002. Éxodo y exilio de los jesuitas españoles según el diario inédito del P. Luengo. Alicante: Universidad de Alicante.

Fernández Sebastián, Javier. 2008. «The Concept of Civilization in Spain, 1754-2005: From Progress to Identity». Contributions to the History of Concepts 4: 81-105. https://doi.org/10.1163/180793207x237740

Gerbi, Antonello. 1960. La disputa del Nuevo Mundo: historia de una polémica (1750-1900). México: Fondo de Cultura Económica.

Giménez, Enrique (ed.). 2002. Y en el tercero perecerán: gloria, caída y exilio de los jesuitas españoles en el siglo XVIII. Alicante: Universidad de Alicante.

Giménez, Enrique. 2012. «Del exilio a la restauración. El debate sobre la Compañía de Jesús entre dos siglos», en Fernando Durán López (ed.), Hacia 1812 desde el siglo ilustrado. Actas del V Congreso Internacional de la Sociedad Española de Estudios del Siglo XVIII: 239-254. Gijón: Trea.

Guasti, Niccolò. 2006. L'esilio italiano dei gesuiti spagnoli: identità, controle sociale e pratiche culturali, 1767-1798. Roma: Edizioni di storia e letteratura.

Guasti, Niccolò. 2009. «Rasgos del exilio italiano de los jesuitas expulsos». Hispania Sacra LXI (123): 257-278. https://doi.org/10.3989/ hs.2009.v61.i123.87

Guasti, Niccolò. 2011. "Catholic civilization and the evil savage: Juan Nuix facing the Spanish conquista of the New World», en Guido Abbatista (ed.), Encountering Otherness. Diversities and Transcultural Experiences in Early Modern European Culture: 285302. Trieste: Edizioni Università di Trieste.

Guasti, Niccolò. 2013. «I gesuiti spagnoli espulsi e le élites italiane di fine Settecento». Annali di storia dell'educazione 20: 147-178.

Guasti, Niccolò. 2014. «Los jesuitas españoles expulsos antes la disputa del Nuevo Mundo», en Antonino De Francesco y Luigi Mascilli (eds.), Entre Mediterráneo y Atlántico. Circulaciones, conexiones y miradas (1756-1867): 93-108. Santiago de Chile: Fondo de Cultura Económica.

Guasti, Niccolò. 2015. "The exile of the Spanish jesuits in Italy (17671815)», en J. D. Wright-Burson (ed.), Jesuit suppression in global context. Causes, events and consequences: 248-261. Cambridge: Cambridge University Press.

Guasti, Niccolò. 2018. «Lorenzo Hervás y Panduro ante los censores de la Real Academia de la Historia. La traducción española de la Idea dell'Universo», en Inmaculada Fernández Arrillaga, Verónica Mateo Ripoll, Manuel Pacheco Albalate y Rosa Tribaldos Soriano (coords.), Memoria de la expulsión de los jesuitas por Carlos III: 479-489. Madrid: Anaya.

Hazard, Paul. 1941. La crisis de la conciencia europea (1680-1715). Madrid: Pegaso.

Mantecón Sardiñas, Sergio. 2014. «Los misioneros jesuitas, traductores culturales: las fronteras culturales de la misión católica en la China del siglo XVIII». Manuscrits. Revista d'història moderna 32: 129-150.

Merlin-Kajman, Hélène. 2005. «"Une troisième espèce de simple dignité", ou la civilité entre l'honneur et la familiarité», en Fanny Cosandey (ed.), Dire et vivre l'ordre social en France sous l'Ancien Régime: 231-279. París: EHESS.

Mestre, Antonio. 2003. Apología y crítica de España en el siglo XVIII. Madrid: Marcial Pons.

Navarro Brotons, Víctor. 2014. Disciplinas, saberes y prácticas: filosofía natural, matemáticas y astronomía en la sociedad española 
de la época moderna. València: Publicacions de la Universitat de València.

Pancera, Carlo. 1986. «Educazione dei costumi e insegnamento delle virtù», en Gian Paolo Brizzi (ed.), Il catecismo e la grammatica: 309-311. Bolonia: II Mulino.

Perdiguero, Enrique. 2003. «Popularizando la ciencia: el caso de la medicina doméstica en la España de la Ilustración», en Josep Lluís Barona, Javier Moscoso y Juan Pimentel (coords.), La Ilustración y las ciencias. Para una historia de la objetividad: 155-178. Valencia: Universitat de València.

Perrone, Nicolás Hernán. 2012. «Una mirada a la comunidad de jesuitas americanos expulsos a través de las obras de Lorenzo Hervás y Panduro S.J. (1735-1809)». História Unisinos 16 (1): 107-117. https://doi.org/10.4013/htu.2012.161.09

Perrone, Nicolás Hernán. 2013. “"Si no eres jesuita serás jansenista; y si no eres jansenista serás jesuita". El problema del jansenismo en Causas de la revolución de Francia de Lorenzo Hervás y Panduro S.J. (1735-1809)». Hispania Sacra LXV (extra II): 203-230. https:// doi.org/10.3989/hs.2013.040

Perrone, Nicolás Hernán. 2017. «La reapropiación de la Antigüedad clásica en el proyecto educativo reformista de Lorenzo Hervás y Panduro S.J. (1735-1809)». Historia y Grafía 25 (49): 197-210.

Ramada Curto, Diogo. 2005. "The Jesuits and Cultural Intermediacy in the Early Modern World». Archivum Societatis lesu LXXV (47): 3-22.
Romano, Antonella. 1999. La contre-réforme mathématlque. Constitution et diffusion d'une culture mathématique jésuite à la Renaissance (1540-1640). Rome: École française de Rome.

Romano, Antonella. 2013. "Un siècle de voyages missionnaires dans la Chine des derniers Ming». Estudis. Revista de historia moderna 39: 67-88.

Romano, Antonella. 2016. Impressions de Chine. L'Europe et l'englobement du monde $\left(16^{e}-17^{e}\right.$ siècles). París: Fayard.

Rubiés, Joan Pau. 2005. "The concept of cultural dialogue and the jesuit method of accommodation: between idolatry and civilization». Archivum Societatis lesu LXXV (47): 237-280.

Rubiés, Joan Pau. 2017. "Ethnography and Cultural Translation in the Early Modern Missions». Studies in Church History 53: 272-310. https://doi.org/10.1017/stc.2016.17

Sebastiani, Silvia, 2011. «Las escrituras de la historia del Nuevo Mundo: Clavijero y Robertson en el contexto de la Ilustración europea». Historia y Grafía 19 (37): 203-236.

Soriano, Nuria. 2013. «Tiempo de memoria, olvido y manipulación: los jesuitas españoles expulsos y la vindicación de la conquista de América». Manuscrits. Revista d'Història Moderna 31: 137-162.

Spence, Jonathan. 2009. La pregunta de Hu. València: Publicacions de la Universitat de València.

Tietz, Manfred. 2001. Los jesuitas españoles expulsos: su imagen y contribución al saber sobre el mundo hispánico en la Europa del siglo XVIII. Madrid - Frankfurt: Iberoamericana - Vervuert. 